\title{
De la radio interactiva a la radio transmedia: nuevas perspectivas para los profesionales del medio
}

\section{From Interactive Radio To Radio Transmedia: New Perspectives For Media Professionals}

Aurora García González

Profesora Titular Doctora (Universidad de Vigo)

Fecha de recepción: 2 de febrero de 2013

Fecha de revisión: 19 de junio de 2013

Para citar este artículo: García González, A. (2013): De la radio interactiva a la radio transmedia: nuevas perspectivas para los profesionales del medio, Icono 14, volumen 11 (2), pp. 251-267. doi: 10.7195/ri14.v11i2.567 


\section{Resumen}

El objetivo principal de este trabajo ha sido localizar y definir los nuevos conceptos que configuran el ámbito científico de la comunicación radiofónica en un contexto caracterizado por la evolución de las tecnologías y su incidencia para la conceptualización de espacio y tiempo imprescindibles en el medio radiofónico. Lo primero que parece advertirse es que está cambiando el mismo concepto de radio.

La metodología utilizada ha sido principalmente la revisión de fuentes para la localización y definición de los nuevos conceptos que conforman el espacio mediático a partir de su forma más consolidada en la bibliografía contemporánea. Se trata pues de un análisis descriptivo, que pretende aportar una versión unificada de los nuevos contenidos en la disciplina comunicación radiofónica. Los resultados permiten ofrecer al menos una aproximación al conocimiento del trabajo de los profesionales de radio en un momento de importantes cambios para el medio.

\section{Palabras clave}

Radio - Transmedia - Comunicación - Tecnologías emergentes - Periodismo

\section{Abstract}

The main objective of this work is to locate and define the new concepts that form the scientific field of radio communication. The context is characterized by the evolution of technology and its impact in the space and time conceptualization necessary in the medium of radio. The first thing that becomes apparent is that radio concept is changing.

The methodology used was the review of sources for locating and defining new concepts from its most consolidated contemporary literature. It is therefore a descriptive analysis, which aims to provide a unified version of new contents in radio communication discipline. The results allow at least provide a better knowledge of the work of radio professionals at a time of significant change for the radio context. 


\section{Key Words}

Radio - Transmedia - Communication - Emerging Technologies - Journalism - Interactivity - professionals

\section{Introducción}

El concepto transmedia, alude a construir una experiencia de inmersión en la que el motivo central del relato alcanza extensiones en plataformas diferentes a la original “las cuales se ofrecen como múltiples puntos de entrada, añaden algo más a la historia y generan un ámbito narrativo envolvente" (Haye, 2011). Sostiene Haye que uno de los aspectos más sugerentes de este complejo entramado de textos y soportes lo constituye el surgimiento de los denominados proyectos de narrativa transmedia, es decir, proyectos que utilizan varias plataformas para llegar a diferentes públicos con su relato y que trascienden el concepto de multimedia. Se trata de una nueva forma de convergencia digital (Rasmussen \& Raudaskoski, 2002).

El concepto no es nuevo, aunque ha sido ahora cuando se ha popularizado, debido a que la técnica digital permite una producción y una traslación sencilla y rápida entre plataformas. Para Rémirez (2012):

“Las obras textuales llevadas al teatro han existido siempre, las películas basadas en novelas son algo casi consustancial con el séptimo arte y la ópera es, desde que se fijan sus reglas modernas con Monteverdi, un ente transmedia claro: arte visual, danza, sonido, libreto, programas de mano complementarios, vestuario, efectos especiales en el escenario, etc. que envuelven al espectador en un todo global. Más aún a partir de la evolución wagneriana y su ideal de obra artística total concentrado en una unidad (gesamskuntswerk) que alcanza manifestaciones tan notables como la tetralogía nibelunga. Sea cuál sea forma en que se muestre lo importante es la historia".

La participación de la radio en este escenario transmedia le está obligando a actualizar toda su capacidad de relato (Ramos, García, Van Haandel \& Piñeiro, 2012). La radio vive actualmente una rupturista transformación motivada por el auge de las nuevas tecnologías, nuevos hábitos y nuevos perfiles (López \& Ortiz, 2011). El universo narrativo radiofónico, en pleno desarrollo, parece vivir un nuevo naci-

DOI: ri14.v1 1i2.567 | ISSN: 1697-8293 | Año 2013 Volumen 11 N² 2 | ICONO14 
miento. La narración reaparece y cobra fuerza en los nuevos soportes radiofónicos, tanto en las webradios como en los bancos de datos de programas.

En todo caso, el concepto transmedia tampoco es nuevo para la radio. Sin embargo, elementos como la rapidez, la variedad, el alcance o la interactividad hacen que las actuales plataformas cobren cada vez más interés. Nos encontramos en la frontera de la tecnología y las nuevas formas de comunicación que están contribuyendo a cambiar el modo de crear, experimentar y compartir historias.

El objetivo principal de este trabajo ha sido localizar y definir los nuevos conceptos que parecen consolidarse en el ámbito científico de la comunicación radiofónica en un contexto caracterizado por la evolución de las tecnologías y su incidencia en la conceptualización de espacio y tiempo tan imprescindibles en el medio radiofónico. Y lo primero que parece advertirse es que lo que está cambiando es el mismo concepto de radio.

\section{Material y Métodos}

El material empleado para la elaboración de este trabajo está integrado por un cuerpo documental que ha permitido el rastreo por los principales autores contemporáneos que han reflexionado sobre la comunicación radiofónica en términos de movilidad donde se está produciendo un transvase de rutinas profesionales desde una consideración interactiva de la radio a una nueva calificación transmediática. Un cambio sustancial que ha revertido en las transformaciones que a continuación se señalan y que afectan a los tres elementos principales del proceso radiofónico: el emisor, el receptor y el mismo producto radiofónico, considerado desde su nueva producción. En este último inciden de manera no ya incipiente las nuevas narrativas transmedia.

La metodología utilizada ha consistido principalmente en la revisión de fuentes para la localización y definición de los nuevos conceptos que conforman el espacio mediático a partir de su forma más consolidada en la bibliografía actual. Se trata pues de un análisis descriptivo, que pretende aportar una versión unificada de los nuevos contenidos en la disciplina comunicación radiofónica. Los resultados permiten ofrecer al menos una aproximación al conocimiento del trabajo de los profesionales de radio en un momento de importantes cambios para el medio.

ICONO14 | Año 2013 Volumen 11 N² 2 | ISSN: 1697-8293 | DOI: ri14.v1 1i2.567 


\section{Resultados}

La radio transmedia parece ser la forma natural de evolución de la radio interactiva. Y en esta nueva forma el trabajo del comunicador radiofónico comienza a redefinirse. Atendiendo a Jenkins (2006) podemos considerar transmedia aquellos relatos interrelacionados que están desarrollados en múltiples plataformas, pero que guardan independencia narrativa y sentido completo.

\subsection{La transformación del contexto: el escenario transmedia}

La radio se ha adaptado siempre bien, en el curso de la historia, a los cambios sobrevenidos por la adopción de nuevas tecnologías. Actualmente desarrolla su actividad en este contexto transmedia (Jenkins, 2006) y se encuentra en pleno proceso de transformación, o "radiomorphosis" (Prata, 2010).

El presente artículo coincide con otros autores en señalar que en esta transformación:

“no es propiamente la tecnología el factor determinante (aunque sea indispensable) de este proceso, sino la experiencia simbólica que relaciona tecnología y significación. No es propiamente la tecnología, sino el lenguaje, lo que permite la comprensión humana de la realidad" (Moragas, 2012).

Y como ha recordado Scolari citando a Jerome Brunner:

“hay dos formas de dar sentido al mundo que nos rodea: una manera lógicoformal, basada en argumentos, y otra narrativa, fundada en los relatos" (Scolari, 2013).

La radio se beneficia de las plataformas multimedia por la digitalización de la producción. Y de las ventajas de la comunicación no-visual que se traducen en poder escuchar haciendo otras cosas (entornos multitask), así como del valor de la relación entre lenguaje radiofónico alejado del mero discurso imitativo (Balsebre, 1999), imaginación y conocimiento. Los recursos de la palabra oída que utiliza el medio se configuran como una poderosa ayuda para potenciar y estimular la atención y la escucha. La lengua como realidad viva contiene su propia dinámica natural. Y es posible valorar el relato como una comunicación más expresiva, más atractiva, más flexible y lúdica, que confiere dinamismo y creatividad al proceso comunicativo.

DOI: ri14.v1 1i2.567 | ISSN: 1697-8293 | Año 2013 Volumen 11 N² | ICONO14 
En este contexto, cada vez reviste mayor importancia la figura del narrador. La radio ha perpetuado la cultura del significante oral, y reconoce en ese su ámbito propio y su mejor peculiaridad. La palabra radiofónica sigue siendo imprescindible. Y como cada vez resulta más difícil encontrar personas que tengan la capacidad de explicar bien las cosas, cobra relieve la figura del conductor de programas que interpreta la realidad. Se hacen imprescindibles personas que tengan la capacidad de explicar las cosas. Son necesarias para explicar, para relacionar una música con una historia, para contar una anécdota al hilo de lo que se emite, o para recuperar un tema olvidado.

Por eso dice Meneses (Meneses, 2012) que la radio de palabra, (informativa o no) tiene más posibilidades de sobrevivir inalterada que la radio musical. Parece, pues, que corresponde a la radio recuperar esa capacidad narrativa, contribuyendo a una cultura del diálogo. Máxime en un momento de auge de la participación.

Este nuevo escenario al que se hace referencia y que constituye el nuevo contexto en que trabaja la radio, reviste ciertas notas características.

Para empezar es un escenario definido por la economía de la atención y el entorno multitask, como se ha señalado. La radio se usa en concurrencia con otras plataformas de información. Y, si ya siempre había tenido la cualidad de permitir la escucha en segundo plano, con la atención alternada, ahora tiene que atender al hecho de que las personas se ven obligadas a dividir la atención hacia diferentes productos mediáticos, y a la realización de actividades simultáneas al consumo de medios.

Las redes sociales han contribuido a crear proximidad con los oyentes, como siempre ha hecho la radio. Facebook o Twitter se han convertido en instrumentos de acercamiento de la audiencia radiofónica. La radio se ve obligada a adaptar los contenidos, para no perder protagonismo entre otros medios. Y como consecuencia, la escucha de radio es cada vez más individualizada y participativa.

Además, se ha centrado eminentemente en el entorno local. La radio, gracias a Internet, tiene a su alcance la distribución internacional de contenidos de origen o de carácter local. No se trata del concepto "local" tal y como se entendía hasta hace relativamente pocos años. Se trata de una radio de proximidad que puede producirse en cualquier parte del mundo. Buena prueba constituye la reciente institución por parte de las grandes cadenas de radio ( $\mathrm{ABC}, \mathrm{BBC} . .$.$) de los "Local Radio$ Awards" para estimular la producción de radio multiplataforma.

ICONO14 | Año 2013 Volumen 11 N² 2 | ISSN: 1697-8293 | DOI: ri14.v1 1i2.567 
Este proceso se vive en circunstancias cambiantes, llamadas de cross media consumption. Actualmente es perfectamente posible escuchar radio mientras se navega por Internet. Y sin embargo faltan programaciones solamente pensadas para la radio. Se trata de una crisis de identidad en los contenidos del medio; el permanente reto de la creatividad. Sería deseable un equilibrio entre la forma de expresión radiofónica y la lógica de mercado, no siempre beneficiada por el intento de mantener el contacto con el consumidor varias veces al día.

Uno de los conceptos más afectados por esta transformación en el ámbito de la radio es el concepto de tiempo, por otra parte uno de los más valiosos para el medio desde sus orígenes, deriando hacia lo que Manuel Castell ha denominado el "tiempo atemporal" (Castells, 2000).

Toda la historia del fenómeno de la comunicación muestra el intento de reducir el tiempo transcurrido entre la producción del hecho y su difusión. La diligencia en disponer de los hechos para darlos a conocer y su efectiva difusión configuran la tendencia a la simultaneidad. En este sentido, la culminación del fenómeno de la comunicación colectiva se alcanza en los medios sincrónicos, de acuerdo con la terminología de Martín Serrano, que permiten una simultaneidad virtual entre el acontecer y su puesta a disposición de los destinatarios. Se trata del ideal de la comunicación colectiva:

"una comunicación en grado potencialmente ilimitado y tendencialmente simultáneo" (López Escobar, 1989).

La radio ha estado marcada siempre por la repetición, particularmente en su vertiente publicitaria, donde se ha utilizado como recurso expresivo. Las actuales facilidades tecnológicas han transformado radicalmente esta nota del hacer radiofónico. La reiteración es libre o eludible, es posible repetir innumerables veces un fragmento favorito o se puede dejar de reproducir.

En esta radio hiperfragmentada se ha modificado el concepto de tiempo. Trabajar en tiempo real, es decir, en 15 segundos, o tiempo que se tarda en tomar una decisión, es un reto difícil de abordar. Un criterio de consumo del oyente actual es la obtención de la mejor información en el menor tiempo posible. Pero al mismo tiempo la audiencia exige contenidos valiosos, veraces y entretenidos, que son la clave para la fidelidad de la audiencia y el desafío para los nuevos creadores contenidos.

DOI: ri14.v1 1i2.567 | ISSN: 1697-8293 | Año 2013 Volumen 11 N² 2 | ICONO14 


\subsection{La transformación de las mentalidades}

Como toda revolución tecnológica la que está viviendo, la radio ha traído consigo su correspondiente transformación de las mentalidades. La rápida evolución desde la interactividad está produciendo algunos cambios de mentalidad.

Lo primero que cambia es la mentalidad del emisor. En la producción radiofónica contemporánea, y más aun en una confluencia transmedia, los receptores comparten el dominio sobre el tiempo. El emisor ya no puede imponer una temporalidad discursiva. La libre navegación recrea en cada oyente el tiempo del relato. El emisor sabe que el receptor organizará el tiempo según su lógica personal, creando sus propios anacronismos. En la radio interactiva se produce una reduplicación de estas anacronismos (Moreno, 2003).

De todas formas, cabe señalar que las emisoras de radio todavía están adaptándose al nuevo contexto, y por el momento continúan haciendo un uso de Internet que muy bien podría calificarse de prudente. Tal vez por un natural temor al relevo generacional (Franquet \& Ribes, 2002), el hecho es que se advierte cierta resistencia a utilizar todas las potencialidades que la web ofrece. La webradio continúa vertebrada por la palabra radiofónica. En este ámbito no existe todavía convergencia mediática, como ha ocurrido con la radio musical a la que es imprescindible coexistir con otras alternativas (Ipod, lectores de música...).

La radio informativa conserva la inmediatez; ni siquiera es preciso someterse a los horarios de emisión, sino que el comunicador (sea profesional o no) puede enviar al aire de manera inmediata sus noticias en el momento en que las obtiene; la distancia temporal es un clic. Y cada corresponsal puede incluir tags procedentes de fuentes sonoras que se recuperan en el ordenador, en el móvil o en cualquier dispositivo on line.

Uno de los cambios más evidentes ha sido trasladar al oyente la facultad de organizar los contenidos y disponer libremente de ellos: elegir qué escuchar, a qué hora hacerlo, modificar aleatoriamente el orden de un informativo, rechazar determinadas informaciones... Presentar, en fin, sus propias producciones, a partir de lo que la radio ofrece.

Son cambios que modifican también la mentalidad de las audiencias. Los nuevos oyentes constituyen audiencias multitasking, es decir escuchan radio mientras navegan, o atienden el correo, participan en un chat, etc. Estas mismas audiencias

ICONO14 | Año 2013 Volumen 11 N² | ISSN: 1697-8293 | DOI: ri14.v11i2.567 
(principalmente jóvenes nativos digitales) paran el video para contestar el móvil, escuchan dispositivos mp3 durante la clase... es decir, ya no consumen lo que se les da, sino que consumen lo que quieren. Es una consecuencia inevitable de la pérdida de importancia de la distribución analógica o hertziana en favor de Internet y la telefonía móvil.

Ante la sobreabundancia de oferta on line cobra nuevo sentido la selección; son los oyentes quienes establecen la selección de contenidos radiofónicos. Aunque en la actualidad haya que ser cautos con las previsiones, pronto será posible construir una programación a partir de la actual lógica de tags, y usando sólo la voz para seleccionar. Es el final de la escucha pasiva, del modelo unidireccional.

Los nuevos oyentes de esta radio de elección (García \& Román, 2008) son, con acierto, considerados prosumers. Controlan y personalizan el consumo de radio. Por una parte, cada vez un número mayor de individuos es capaz de ofrecer información, y a coste más bajo. Por otra, la escucha de radio se hace de manera personalizada: cada oyente organiza su propio playlist, o el orden en que quiere escuchar unas noticias.

De la misma manera cada vez son más abundantes los blogs, los podcast al margen de la industria y los mashups (híbridos construidos como nuevos elementos a partir de producciones anteriores), como ocurre en el caso de YouTube o MySpace, y es más evidente que el consumo de radio se asocia a redes sociales, en las que gustos y preferencias son compartidos con otras personas. Lo que las redes sociales hacen es organizar de una forma más ágil o más inteligente los perfiles o los contenidos que interesan.

La verdadera potencia del cambio ha sido la interactividad que ha permitido a la radio intercambiar los roles de emisor y receptor. Y comentar, intervenir y a su vez contestar las demandas de los oyentes. De todas formas, todavía no se ha producido el cierre de circuito en el modelo radiofónico, dado que las intervenciones de respuesta al oyente son tímidas, pero es una vía abierta y potenciada por Internet.

\subsection{El profesional de radio en el nuevo entorno}

Las transformaciones que han afectado a la radio desde la irrupción de Internet y el surgimiento de la webradio, con emisión en streaming, han afectado incluso al entorno de trabajo del periodista radiofónico. Los estudios de radio incorporaron

DOI: ri14.v1 1i2.567 | ISSN: 1697-8293 | Año 2013 Volumen 11 N² 2 | ICONO14 
cámaras para la emisión de programas.

El propio trabajo exige la incorporación de textos, imágenes, gráficos y videos. Rápidamente, la radio tuvo que dotarse de páginas web (sites) o blogs sobre los programas, con informaciones que pudieran resultar útiles sobre los mismos, sus orígenes, su presente, su pasado... Igualmente, hubo que crear links o enlaces para asociar cada música que se emite, en tiempo real, con su letra (y hasta con su traducción), o con un videoclip; con informaciones sobre el grupo musical por ejemplo, en forma de imágenes o de texto, y sobre el tema con enlaces a la página oficial, o a una dirección electrónica, abierta a los comentarios sobre la emisión. Se multiplicó, asimismo, el uso del podcast con contenido informativos, o incluso con cada noticia de un informativo de manera, que el consumidor (utilizador) pueda reorganizarlo a su gusto (Gallego, 2010). Cualquier oyente puede construir hoy su propio informativo.

Todo ello con las consiguientes repercusiones en el trabajo que desempeñan los periodistas, que han visto como sus jornadas de trabajo y nivel de responsabilidad iban en aumento a pesar de las facilidades propiciadas por los avances tecnológicos (Tapia, López, Medina \& Gómez, 2006).

\subsubsection{El trabajo del periodista}

El trabajo del periodista de la radio siempre se ha caracterizado por la inmediatez. Y eso sigue siendo posible en el nuevo entorno multiplataforma en el que pervive la capacidad de la radio para informar. No siempre es posible, cuando se necesita alguna información, poder interactuar, acudir a Internet o al ordenador para obtener información. La radio continúa siendo un medio privilegiado en cuanto a la inmediatez.

Como se ha señalado, la radio se ha adaptado siempre bien al cambio tecnológico, y de hecho sigue siendo un pilar estructural del nuevo mundo "tecnologizado" de la comunicación. Los cambios que se han registrado han incidido sobre todo en el discurso radiofónico, que en sus comienzos era más formal y ahora lo es cada vez menos. El criterio de supervivencia era la voz: disponer de una buena voz 0 educarla y modularla al servicio de los contenidos, ante una audiencia eminentemente pasiva. La conversación es más informal y se advierte que ha habido una revolución en los modos de trabajar que ha revertido sobre los modos de hablar.

ICONO14 | Año 2013 Volumen 11 N² 2 | ISSN: 1697-8293 | DOI: ri14.v11i2.567 
En anteriores publicaciones se ha estudiado el impacto de las nuevas tecnologías y su influencia en los cambios de narrativa radiofónica (Ramos, García, Van Haandel \& Piñeiro, 2012).

La radio actual incorpora todas las formas de multitarea (blogs, vídeos...), lo que ha supuesto un desafío gigantesco para los periodistas que trabajan en el medio. Las plataformas, indudablemente, han ayudado a conseguir oyentes. Facebook por ejemplo, aunque parezca agotado como concepto, continúa atrayendo audiencias. Pero estos oyentes suponen un contingente de interactividad que está haciendo cambiar la radio, desde los contenidos hasta las rutinas profesionales de los periodistas. Facebook también ha servido para localizar fuentes o conseguir entrevistas. Las nuevas plataformas y las redes sociales son utilizadas por el periodista como antes usaba la agenda.

Los periodistas radiofónicos han tenido que aprender necesariamente otros lenguajes, y utilizar nuevas herramientas, no sólo la voz; han tenido que adoptar otros formatos, por imposición de la evolución de las tecnologías y el advenimiento de otras formas de aprovisionamiento mediático. Aquella radio intimista de los comienzos de su historia ha evolucionado; Internet ha abierto el espacio radiofónico, porque ha acostumbrado a los oyentes a otras dimensiones y a las actividades simultáneas.

Internet puede prolongar el trabajo que realizan los periódicos, de manera muy similar a lo que hizo la radio en sus orígenes, cuando impulsó sus diarios hablados, antes de encontrar su propio lenguaje. Los investigadores suelen decir que Internet está siendo desaprovechado por parte de las emisoras de radio, pero se advierte cierta incoherencia en esta afirmación, pues los propios periodistas están multiplicando sus formas de trabajar y han emprendido nuevas iniciativas (Rodero \& Sánchez, 2007).

\subsubsection{La narrativa radiofónica}

El empleo de Internet también ha introducido cambios en la narrativa radiofónica, todavía no suficientemente estudiados. Es importante profundizar en su conocimiento para mejorar la eficacia comunicativa. Las emisoras, desde el advenimiento de la red, han potenciado nuevas formas de creación, transmisión e intercambio de contenidos.

DOI: ri14.v1 1i2.567 | ISSN: 1697-8293 | Año 2013 Volumen 11 N² 2 | ICONO14 
La narración es el modo natural de la comunicación entre personas, sobre todo si entendemos por comunicación no un mero transmitir informaciones, sino un intento de lograr establecer un contacto entre seres humanos (Martín Algarra, 1993). La radio es un medio que reproduce muy bien la forma natural de comunicarse las personas. En este sentido es el más natural de los medios de comunicación. Pero la tecnología condiciona el modo en el que comprendemos el mundo. Las nuevas tecnologías aportan nuevas historias, nuevas visiones del mundo. Con cada incorporación, los tipos de relatos se han visto abocados a coexistir, dándose con el tiempo las inevitables influencias mutuas.

La radio actual, muchos años después de su edad de oro, continúa utilizando el relato, no sólo en su vertiente informativa, sino incluso en aquella que es su producción primigenia y específica, la publicidad. La narrativa radiofónica vincula estrechamente al receptor con la realidad que se comunica. La voz hace presente la historia ante el oyente de una manera que impacta en la esfera emocional. La mayoría de las personas concede más credibilidad al conocimiento recibido a través de una anécdota que alguien cuenta.

“Muchos de nosotros damos más peso a esta clase de historias porque son extremadamente vívidas y basadas en un relato personal, detallado, cada a cara" (Schwartz, 2004).

Por otra parte no existe un único modelo de narración radiofónica, sino que es preciso abordar una pluralidad creciente de maneras de contar lo que ocurre. Esta versatilidad y adecuación a los tiempos sociales ha hecho de la radio un medio capaz de sortear circunstancias históricas complejas y difíciles, lo cual nos pone sobre la pista de uno de los elementos más interesantes en el caso que nos ocupa: la permanencia del relato como elemento esencial para la comunicación en la webradio.

Muchos guionistas y contadores de historia pueden resultar favorecidos en esta coyuntura puesto que la emergencia de este escenario de complementariedades mediáticas habilita nuevas alternativas laborales. Por otro lado, el modelo demanda una construcción coral de los relatos, algo que sin duda puede contribuir a enriquecerlos.

“En el caso de la narrativa, no importa tanto que sea verdad sino que sea verosímil" (Scolari, 2013).

Lograr la amplificación de ese impacto emocional sólo puede conseguirse por la

ICONO14 | Año 2013 Volumen 11 N² | ISSN: 1697-8293 | DOI: ri14.v1 1i2.567 
convergencia hábil, coordinada y estudiada de las diversas plataformas que componen una obra transmedia. El relato transmedia puede ser el recurso más útil del que disponemos a día de hoy.

\subsection{Notas para la redacción del relato transmediático}

El concepto de transmedia es, por otra parte aplicable en cualquier situación en la que intervenga un proceso narrativo. Suelen señalarse cuatro claves, extraídas de la 4th "Futures of Entertainment" Conference, para la nueva era que la radio comienza:

a) Las historias deben ser penetrantes. Jenkins, que acuñó el término transmedia, ha resaltado ya la "penetrabilidad" como el principio clave de la narración transmedia, destacando la importancia de crear narrativas capaces tanto de difundirse fácilmente como de calar hondo en el receptor. Mientras que muchos de los actuales expertos en comunicación se centran más en la expansión horizontal de las narrativas (a través de plataformas, redes, usuarios, etc.), es precisamente su capacidad de expansión vertical, su penetrabilidad, la que establece las duraciones auténticas.

b) Cada parte de una historia ha de ser enriquecedora, pero no esencial, para la experiencia global. Conforme la narración deje de estar confinada a los canales tradicionales, las historias fluirán, reaccionarán y se adaptarán a los nuevos formatos. No obstante, cada parte de la historia, ya sea una cuña o un episodio web ("Easy to Assemble" de Ikea o el vídeo "Day of Light" lanzado en la red al inicio de 2013), enriquece la narración global sin llegar a constituir un elemento esencial de su desarrollo. Ninguna manifestación o plataforma debe ser indispensable para la comprensión de la trama principal, pero cada porción debe contribuir a enriquecer el conjunto.

c) Comprender cómo crear un grupo sólido de seguidores es uno de los retos más importantes que afrontan hoy en día los creadores de contenidos en radio. Gracias a Internet, los fans han cobrado una mayor importancia, y la relación entre el creador y su audiencia, antes estática, ha devenido en un diálogo en tiempo real, que permite incluso la colaboración entre ambos. Las reacciones surgen en múltiples formatos (desde la remezcla del material hasta las parodias, pasando por

DOI: ri14.v1 1i2.567 | ISSN: 1697-8293 | Año 2013 Volumen 11 N² 2 | ICONO14 
webs dedicadas a nuestra obra). Conviene que los creadores comiencen a considerar a sus audiencias como co-creadores de sus narrativas en lugar de como barómetros.

d) En última instancia, el objetivo no es crear sólo una historia, sino también un mundo alrededor de ella. El cuarto principio de la narrativa transmedia, según Jenkins, se centra en la importancia de crear un mundo en el que nuestra historia pueda ubicarse.

\section{Discusión}

La aproximación al conocimiento del trabajo del profesional de la radio en un momento de importantes cambios, que la evolución tecnológica permite definir como contexto transmedia, ha permitido al menos señalar estas consideraciones resultantes:

- La exploración de estrategias de comunicación transmedia entre las diversas plataformas de comunicación ha posibilitado la creación de entornos de comunicación con un elevado nivel de interacción, de gran riqueza informativa, cognitiva y emocional. Actualmente, este tipo de escenarios está siendo explorado con resultados muy interesantes y prometedores con respecto a sus complementariedades.

- En este entorno cobra cada vez más valor la investigación, búsqueda y recuperación de documentos multimedia (textos, audio, vídeo, imágenes, etc.) que pueden ser utilizados en múltiples plataformas tecnológicas en las que el componente móvil ha venido a tener una gran presencia.

- La webradio parece el estado actual al que la evolución tecnológica ha llevado a la radio en su permanente reinvención. Presenta así un potencial que resulta de las características comunicacionales diferenciadoras típicas de la radio: ubicuidad, simplicidad, flexibilidad e intimismo. Estas características garantizan una perennidad conceptual que justifica la atención investigadora al papel de la radio en general, o de la webradio en particular, en contextos transmedia, ya sea en los planos tradicionales de la radio (informativo y de entretenimiento), ya sea en los nuevos planos como la educación y la formación.

- En contextos transmedia, la radio hertziana sigue teniendo su lugar y puede afirmarse que ha evolucionado rápidamente por debajo, incluso, de los radares de los media studies, y es difícil seguirla; aunque hay que admitir que ha sabido 
adaptarse a los cambios impuestos por la última revolución tecnológica.

- En suma, los recursos de la palabra oída que la radio utiliza son una poderosa ayuda para potenciar y estimular la atención y la escucha. El lenguaje, en cuanto realidad viva, contiene una dinámica natural de gran riqueza que permite valorar el relato como una comunicación expresiva, atractiva, flexible y lúdica, que confiere dinamismo y creatividad al proceso comunicativo. Y por ende sostiene la argumentación.

\section{Referencias}

Balsebre, A. (1999). El lenguaje radiofónico. Madrid: Ediciones Cátedra.

Franquet, R., Ribes, X. (2002). La transición digital pendiente de la migración. Àrea Abierta. No 4. Madrid: Universidad Complutense. Recuperado de http:// revistas.ucm.es/inf/15788393/articulos/ARAB0202330006A.pdf.

Gallego Pérez, I. (2010). Podcasting. Nuevos modelos de distribución para los contenidos sonoros. Barcelona: UOC.

García González, A., Román Portas, M. (2008). La función participativa de la radio: Programas de participación y comportamiento de las audiencias en la radio autonómica de Galicia. En VV.AA. Jornalismo e democracia representativa. Oporto: Servicio de Publicaciones de la Universidad Fernando Pessoa.

Haye, R. (2011). Sobre o rádio do futuro. En Rádio-Leituras. Ano II, Num 01 Enero-Julio 2011. Universidade Federal de Santa María (Brasil) Disponible en http://radioleituras.wordpress.com. 13 Marzo 2012.

Jenkins, H. (2006). Convergence culture: where old and new media collide. Nueva York: NY University Press.

López-Escobar, E. (1989). Ciencia de la prensa y estudios sobre la comunicación colectiva, nota preliminar a Mcquail, D. y Windhal, S. Modelos para el estudio de la comunicación colectiva. Pamplona: Eunsa.

López Vidales, N., Ortiz Sobrino, M.A., (2011). Radio 3.0. Una nueva radio para una nueva era. La democratización de los contenidos. Madrid: Fragua.

Martín Algarra, M. (1993). Sobre la complejidad terminológica de la teoría de la comunicación. En Estudios de periodismo. La Laguna, v. 2, p. 7-26.

Meneses, J.P. (2012). Estudos sobre a rádio. Oporto: Mais Editora. 
Moreno, I. (2003). Narrativa audiovisual publicitaria. Barcelona: Paidós.

Ramos, F., García, A., Van Haandel, J. \& Piñeiro, Ma T. (2012). Radiomorfose em contexto transmedia. En Campalans, C. Porto Renó, D. y Gosciola, V. Narrativas transmedia. Entre teorías y prácticas. Bogotá: Universidad del Rosario.

Rasmussen, T.A., Raudaskoski, P. (2002). Cross Media and (Inter)Active Media Use. A Situated Perspective. Recuperado de http://www.nordicom.gu.se/ common/publ_pdf/81_313-326.pdf (Acceso 30 de enero de 2013).

Remírez, F. (2012). Recuperado de http://biblumliteraria.blogspot.com (Acceso en 8 de enero de 1012).

Scolari, C. (2013). Narrativas transmedia. Deusto: Grupo Planeta.

Tapia, A., López, N., Medina, E. \& Gómez, P. (2006). La memoria del periodismo. Anàlisi 33 (119-133). Recuperado de http://ddd.uab.cat/pub/ analisi/02112175n33p119.pdf

\section{Bibliografía}

Aguado-Terrón, J.M., Martínez Martínez, I.J. (2009). De la web social al móvil 2.0: el paradigma 2.0 en el proceso de convergencia mediática de la comunicación móvil. Barcelona: El profesional de la información.

Bustamente, E. (coord.) (2003): Hacia un nuevo sistema mundial de comunicación. Las industrias culturales en la era digital. Barcelona: Gedisa. Cardoso, G.. (2009). Da comunicação de massa para a comunicação em rede. En Cardoso, G., Cadima, F. R., Cardoso, L. L. (2009). Media, redes e comunicação: Futuros pensantes. Lisboa: Quimeras Editores.

Cebrián Herreros, M. (1995). Información radiofónica. Mediación técnica, tratamiento y programación. Madrid: Síntesis.

Eno, B. (2013). Day of Light. Recuperado de http://youtu.be/4H0aflNXCGo (Acceso 30 enero de 2013)

Kischinhesky, M. (2009). Cultura da portabilidade. Novos usos do rádio e sociabilidades em mídia sonora. Observatorio $\left(O B S^{*}\right)$. Journal, Lisboa, v. 8. p. 223-238. 
Martí, J. M. (1990). Modelos de programación radiofónica. Barcelona: Feed-Back Eds.

Martínez Costa, M. P., Díaz De Unzueta, J. R. (2005). Lenguaje, géneros y programas de radio: Introducción a la narrativa radiofónica. Pamplona: Eunsa.

Meditsch, E. (2010). A informação sonora na webemergência: sobre as possibilidades de um radiojornalismo digital na mídia e pós-mídia. En Magnoni, A. F., Carvalho, J. M. De. (Org.) (2010). 0 novo rádio: Cenários da radiodifusão brasileira na era digital. São Paulo: Senac.

Menduni, E. (2001). Il mondo della radio. Bologna: Il Mulino.

Nyre, L., Ala-Fossi, M. (2008). The next generation platform: Comparing audience registration and participation in digital sound media. Journal of Radio \& Audio Media, Victoria, v. 15, n.1, 2008. pp. 41-58.

Pessoa, S. (2012). Radio e tecnologías digitais: desafios para a formação do jornalista. Recuperado de http://www.bocc.ubi.pt (Aceso 3 Marzo de 2012)

Prata, N. (2010). A webradio e geração digital. En Ferareto, L.A., Klöckner, L. (2010). Novos horizontes midiáticos. E o rádio?, Porto Alegre: Edipucrs, 2010. pp. 617-631. Recuperado de http://www.pucrs.br/orgaos/edipucrs (Acceso 10 Marzo 2011).

Rodero Antón, E., Sánchez Serrano, C. (2007). Radiografía de la radio en España. Revista Latina de Comunicación Social, 62. Recuperado de en http://www.ull. es/publicaciones/latina/200714RoderoySanchez.htm (Acceso, 29 de enero de 2012).

Schwartz, B. (2004). The paradox of choice. Nueva York: CCCO. 